Article

\title{
Determining and Evaluating the Hydrological Signal in Polar Motion Excitation from Gravity Field Models Obtained from Kinematic Orbits of LEO Satellites
}

\author{
Justyna Śliwińska *(D) and Jolanta Nastula $(\mathbb{D}$ \\ Space Research Centre, Polish Academy of Sciences, 00-716 Warsaw, Poland \\ * Correspondence: jsliwinska@cbk.waw.pl
}

Received: 27 June 2019; Accepted: 27 July 2019; Published: 30 July 2019

check for updates

\begin{abstract}
This study evaluates the gravity field solutions based on high-low satellite-to-satellite tracking (hl-SST) of low-Earth-orbit (LEO) satellites: GRACE, Swarm, TerraSAR-X, TanDEM-X, MetOp-A, MetOp-B, and Jason 2, by converting them into hydrological polar motion excitation functions (or hydrological angular momentum (HAM)). The resulting HAM series are compared with the residuals of observed polar motion excitation (geodetic residuals, GAO) derived from precise geodetic measurements, and the HAM obtained from the GRACE ITSG 2018 solution. The findings indicate a large impact of orbital altitude and inclination on the accuracy of derived HAM. The HAM series obtained from Swarm data are found to be the most consistent with GAO. Visible differences are found in HAM obtained from GRACE and Swarm orbits and provided by different processing centres. The main reasons for such differences are likely to be different processing approaches and background models. The findings of this study provide important information on alternative data sets that may be used to provide continuous polar motion excitation observations, of which the Swarm solution provided by the Astronomical Institute, Czech Academy of Sciences, is the most accurate. However, further analysis is needed to determine which processing algorithms are most appropriate to obtain the best correspondence with GAO.
\end{abstract}

Keywords: earth rotation; polar motion excitation; hydrological angular momentum (HAM); low-Earth-orbit (LEO) satellites

\section{Introduction}

The accurate determination of spatial and temporal changes of the Earth's gravity field is essential in many applications, including solid Earth science, hydrology, oceanography, glaciology, and geodesy. The gravity field varies in space and time due to disturbances in mass redistribution of Earth's surficial fluids, which include the atmosphere, oceans, and the land hydrosphere. These variations cause changes in Earth orientation parameters (EOPs), which describe the rotation of the planet. These parameters are: precession/nutation, polar motion (PM) and length-of-day (LOD) variations. EOPs are essential for a number of applications, including precise positioning and navigation in space and on the Earth's surface, pointing of astronomic instruments, and communication with deep space objects. Such great importance of these parameters results from the fact that they are necessary variables for transforming coordinates between a terrestrial reference frame (in which coordinates of ground stations are commonly available and used in all surveying tasks) and a celestial reference frame (in which the coordinates of ground stations are determined from space geodesy techniques such as Global Navigation Satellite Systems (GNSS)) because they provide the rotation between these two frames as a function of time. 
$\mathrm{PM}$ is represented by time series of $\mathrm{x}$ and $\mathrm{y}$ pole coordinates and it describes changes in the orientation of the Earth's rotational axis in relation to the terrestrial reference frame. In 2002-2017, the Gravity Recovery and Climate Experiment (GRACE) mission has given an unprecedented view on global surface mass variations that affect Earth's rotation [1,2]. Assessment of the impact of land hydrosphere on PM has been successfully conducted using GRACE temporal models. However, the data gap between GRACE and its successor, GRACE Follow-On (GRACE-FO), is about one year. For this reason, many scientists have proposed to fill this gap using alternative sources of gravimetric data. The high-low satellite-to-satellite tracking (hl-SST) method could represent such an alternative. This concept uses the so-called kinematic orbits of the low-Earth-orbit (LEO) satellites. The trajectory of such satellites is determined using kinematic point positioning of satellite with the use of GNSS data. The comparison of modeled and measured trajectory of the satellite can provide us with information on the gravitational perturbations of satellite motion.

The conventional method to develop temporal models of Earth's gravity field based on GRACE observations is to use the low-low satellite-to-satellite tracking (ll-SST) concept [3,4]. In this mode, two twin-satellites are placed at the same low orbit with a specified distance between them. The co-orbiting satellites measure distance variations between each other, using high-accuracy measurement systems, such as the microwave or laser ranging system. The measured distance variation between the two satellites, after reducing non-gravitational forces provided by accelerometer measurements, is expected to reflect the gravity perturbation differences between the two locations. To date, GRACE and GRACE-FO are the only missions which have used this concept.

As an alternative to the 1l-SST method, the hl-SST method can be used to determine Earth gravity field models. In this mode, an LEO satellite is tracked by several higher-orbit satellites, namely navigation satellites at a medium Earth orbit (MEO) [3,4]. Since the orbits of MEO satellites are not as intensively disturbed by the gravitational field as orbits of LEO satellites, the orbits of MEO satellites can be modelled sufficiently accurately using existing gravity field models. Therefore, the positions of the MEO satellites are known as reference positions for determining the location of the LEO satellite, of which the orbit is disturbed by the changes of the gravity field. The position of the lower satellite can be determined because it is equipped with a GNSS receiver. Because all low-orbiting objects are exposed to the influence of the Earth's gravitational field, each satellite carrying a geodetic GNSS receiver can be used to generate a gravity model using hl-SST. However, the accuracy of the gravity field solutions developed using this method depends on the quality of the determined satellite position, as well as the height and inclination of a satellite orbit.

Kinematic orbits are the satellite coordinates changes given at specified time intervals (usually every second) or simply on a satellite trajectory, determined using kinematic point positioning with the use of GNSS data. In contrast to the dynamical orbit determination, this method allows recovering the orbit of the satellite without making use of any a priori gravity field information. In recent years, a few institutes have developed and made available gravity field models from kinematic orbits of LEO satellites. For this purpose, they used observations from not only satellites solely dedicated to Earth gravity field monitoring, such as GRACE, CHAllenging Minisatellite Payload (CHAMP), and Gravity field and steady-state Ocean Circulation Explorer (GOCE), but also a number of non-dedicated satellites, including altimetry satellites, radar satellites, weather satellites, Earth-observation satellites, magnetic field monitoring satellites, and others. Initially, the Institute of Theoretical Geodesy and Satellite Geodesy (ITSG) of the Graz University of Technology, Austria has provided temporal gravity field models computed using both dedicated and non-dedicated satellites as well as some combined solutions [5,6]. Alternative data are CHAMP-, GRACE-, and GOCE-based models provided by the Astronomical Institute, Czech Academy of Sciences in Prague (ASU CAS) [7] and models that use kinematic orbits of Swarm satellites [8] solely dedicated to magnetic field monitoring-independent models provided by ASU CAS [9], the Institute of Geodesy and Geoinformation, University of Bonn, Germany [10] and the Astronomical Institute of the University of Bern, Switzerland [11]. 
Recent studies $[10,12,13]$ have evaluated a few different hl-SST gravity field solutions obtained from orbits of Swarm satellites, using GRACE 11-SST observations for this purpose. The results from different institutes vary substantially, mainly due to different maximum degrees and orders of spherical harmonic representation of the geopotential and differences in gravity field estimation approaches and background models $[12,13]$. However, it has been stated that Swarm data could be able to cover the data gap between GRACE and GRACE-FO missions with satisfactory accuracy [9-12]. Moreover, some attempts to combine different Swarm solutions [12,13] have produced promising results and improved accuracy has been obtained. However, although the orbits of Swarm satellites have similar height and inclination as GRACE twin-satellites, they do not provide such high-quality data. The authors of Reference [13] showed that the satisfactory agreement between mass changes based on Swarm and GRACE data could be obtained when the coefficients of spherical harmonics representation of Earth's gravity field up to degree and order 15 is used. They demonstrated that the correlations between GRACE and Swarm estimations decrease sharply above degree 10, and the errors in Swarm estimates increase visibly above degree 15 . They also showed that the higher consistency between GRACE and Swarm mass variations could be obtained in the periods of low solar activity. Indeed, due to their orbit inclination and altitude, the material from which they are built, and the characteristics of instruments aboard, Swarm satellites may be more sensitive to the solar activity. As a result, they produce noisier solutions than the GRACE-based ones.

The authors of Reference [5] evaluated monthly gravity field solutions based on kinematic orbits of GRACE A \& B, GOCE [14], Swarm A, B \& C [8], TanDEM-X [15], TerraSAR-X [16], MetOp-A, MetOp-B [17], and COSMIC [18] satellites and compared them with the results obtained from the GRACE CSR RL05 (Center for Space Research Release 5) solution [19]. The comparison of degree variances of the solutions based on observations from different satellite missions confirms they could all be used to estimate Earth's gravity field, but with different accuracies. The COSMIC, MetOp-A, and MetOp-B data provide results clearly inferior to the solutions obtained from other missions. Reference [5] suggests that this is mainly due to higher orbital altitude and worse GNSS positioning accuracy. For low degrees of geopotential, the TerraSAR-X, TanDEM-X, and Swarm satellites give comparable results to those obtained from GRACE and GOCE gravimetry satellite orbits. However, in the case of the Swarm mission, although two of the three satellites are orbiting at a lower altitude $(430 \mathrm{~km})$, the results are promising only if the data from all three satellites are combined [5].

Other studies have also shown that hl-SST can be useful for deriving long-wavelength gravity signals, related to several circumstances, e.g., mass changes over large river basins and ice sheets or glacial isostatic adjustment (GIA) signals [20]. References [21] and [22] show that combined hl-SST models based on either dedicated plus non-dedicated or only non-dedicated satellite data are able to estimate large-scale mass variations, annual signals, and trends. However, the solutions are limited because of a spatial resolution no better than $750 \mathrm{~km}$ and a high noise level [23]. Moreover, to achieve the best possible accuracy, several conditions should be taken into account during selection of the satellites, i.e., low altitude of the orbit (below $600 \mathrm{~km}$ ), to provide an appropriate sensitivity of the satellite for gravity field variations, high inclination to avoid a polar gap in data, and good quality of GNSS observations. Some improvement in the accuracy of derived gravity field variations due to mass changes can be obtained through combining hl-SST data with satellite laser ranging (SLR) measurements [20,23].

In this study, we examined the usefulness of several global temporal gravity field models determined from kinematic orbits of selected LEO satellites (hl-SST technique) in designating PM variations. The variations of PM due to mass redistribution changes in the Earth's surficial fluids (atmosphere, ocean, and land hydrosphere) can be expressed as $\chi_{1}$ and $\chi_{2}$ components of the PM excitation function (atmospheric angular momentum (AAM), oceanic angular momentum (OAM), and hydrological angular momentum (HAM), respectively). The temporal variations of the $\chi_{1}$ and $\chi_{2}$ components are proportional to the changes of $C_{21}$ and $S_{21}$ (degree- 2 order-one) coefficients of geopotential, respectively [24]. This relationship allows us to use global temporal gravity field models 
to quantify mass-related PM excitation. The GRACE monthly solutions, based on precise range-rate measurements between two satellites (ll-SST), have been widely used for this purpose following extensive research in recent years [25-31]. Special interest has been placed on HAM, as AAM and OAM are well established [32-38].

The assessment of gravity field models based on hl-SST measurements presented in this study was performed to find the most appropriate solution to bridge the gap between GRACE and GRACE-FO. Similar estimations have been performed by other authors $[9,10,12]$. However, all of these previous analyses are based mainly on comparison of degree variances of the solutions or regional water mass changes over ocean, land, and ice sheets. Such types of analyses require full spherical harmonic representation of the geopotential. Here, we focused our attention on PM variations that are described by the $C_{21}$ and $S_{21}$ coefficients only. However, it should be kept in mind that all five EOPs are equally important for transforming station coordinates between the celestial and terrestrial reference frames. Nevertheless, the mass variations of land hydrosphere, of which impacts on the Earth's rotation are analysed here, have a smaller impact on precession/nutation and LOD. Moreover, precession and nutation are well described by theoretical models.

In this study, we compared the hydrological part of mass-related PM excitation functions, expressed as HAM and derived from a number of hl-SST gravity field models. We not only considered the time series of these excitations, but also decomposed them into linear trends, seasonal, and non-seasonal oscillations. The study of the accuracy of these estimates was based on comparisons with reference data, the 1l-SST GRACE ITSG 2018 solution [39], and hydrological signals in observed PM derived from precise geodetic measurements (also called geodetic residuals, GAO). Quantitative analyses were conducted based on comparison of correlation coefficients with reference data and the standard deviation (STD) of the series. This study aimed to identify the solutions that, on the one hand, could best match geodetic and gravimetric observations of PM and, on the other hand, cover the time period of the gap between GRACE and GRACE-FO. Finding such solutions is essential for providing consistent, uninterrupted, and high-quality PM data, which are needed in many geodetic applications.

\section{Materials and Methods}

\subsection{Reference Data}

To evaluate HAM functions obtained from models based on kinematic orbits of LEO satellites, we compared them with two reference series: (i) the hydrological signal in geodetically observed PM excitation (GAO), and (ii) the HAM function obtained from the latest monthly GRACE gravity field model ITSG 2018.

\subsubsection{Hydrological Signal in Observed Polar Motion}

The observed geodetic PM excitation (geodetic angular momentum, GAM) was computed from precise pole coordinates provided by space geodesy techniques such as GNSS, SLR, and very long baseline interferometry (VLBI). The equatorial components $\left(\chi_{1}\right.$ and $\left.\chi_{2}\right)$ of GAM can be calculated from $x$ and y pole coordinates by solving Liouville's equation $[40,41]$. The coordinates of the Earth's pole are available in the daily combined C04 series of EOPs [42,43] provided by the International Earth Rotation and Reference System Service (IERS) (https://www.iers.org/). To obtain the hydrological signal in observed excitation, GAM was reduced for the effects of atmosphere and ocean, using AAM and OAM:

$$
\mathrm{GAO}=\mathrm{GAM}-\mathrm{AAM}-\mathrm{OAM}
$$

The expression GAO-AAM-OAM is usually shortened by taking only the first letters of GAM, AAM, and OAM to obtain G-A-O or simply GAO. Such residual series, denoted as geodetic residuals or GAO, reflect not only the impact of the land hydrosphere, but also barystatic sea-level changes due to the inflow of water from land into the oceans and some solid Earth-related signals, including tectonic signals and GIA, on PM excitation. While GAM is obtained from geodetic measurements, 
AAM and OAM are usually computed using the atmospheric pressure and wind speed, and ocean bottom pressure and currents. These variables can be obtained from geophysical models of atmosphere and ocean.

The following data sets were used to compute GAO:

1. $\chi_{1}$ and $\chi_{2}$ equatorial components of the GAM series, derived from the IERS website (https: //www.iers.org/), available at a temporal resolution of $24 \mathrm{~h}$;

2. $\chi_{1}$ and $\chi_{2}$ equatorial components of the AAM series provided by the GeoForschungsZentrum (GFZ) in Potsdam, Germany, and based on the European Centre for Medium-Range Weather Forecasts (ECMWF) model [44], available at a temporal resolution of $3 \mathrm{~h}$ (data available at http://rz-vm115.gfz-potsdam.de:8080/repository). The current AAM version provided by GFZ is consistent with GRACE AOD1B RL06 (Atmosphere and Ocean De-Aliasing Level-1B Release-6) data $[45,46]$;

3. $\chi_{1}$ and $\chi_{2}$ equatorial components of the OAM series provided by GFZ and based on Max Planck Institute Ocean Model (MPIOM) model [47], available at a temporal resolution of $3 \mathrm{~h}$ (data available at http://rz-vm115.gfz-potsdam.de:8080/repository). The current OAM version provided by GFZ is consistent with GRACE AOD1B RL06 data $[45,46]$.

\subsubsection{GRACE ITSG 2018 Solution}

The GRACE GSM data have the form of monthly time series of spherical harmonic coefficients of the Earth gravity field, with a specified maximum degree and order (d/o) (typically 60, 90, or 120). The non-tidal short-term atmospheric and oceanic signals were removed from the series, and therefore they reflect the impact of mass effects from land hydrosphere, the barystatic sea-level changes, GIA, and tectonic signals resulting from large earthquakes.

Recently, the leading GRACE data centres, including GFZ in Potsdam, Germany; Center for Space Research (CSR) in Austin, USA; the Jet Propulsion Laboratory (JPL) in Pasadena, USA; and the ITSG of the Graz University of Technology, Austria, have provided the newest temporal gravity field solutions, with updated processing algorithms and background models [39,48-50].

In this study, we used the newest GRACE ITSG 2018 solution provided by the ITSG [39]. The motivation for this choice was that most of gravity field models from kinematic orbits of LEO satellites used in this study are also provided by this institute, so the processing methods and background models used are similar. Moreover, our previous researches [51-53] show that compared with series from other institutes, ITSG 2018 provides the highest correlation, variance, and trend agreement with GAO. However, it should be kept in mind that the consistency between GRACE-based HAM functions and GAO depends on specific oscillation and time period considered [51-53]. In general, the HAM trends from GRACE are usually stronger than GAO trends, especially for $\chi_{1}$ component. In terms of amplitudes of oscillations, for some oscillations, they are stronger for GAO while for other they are weaker. Based on numerous comparisons of different oscillations in HAM series computed from different GRACE solutions, we indicated that ITSG 2018 provides the highest consistency with GAO in the largest number of cases [51-53]. The ITSG 2018 series have quasi-monthly time resolution, maximum d/o 60 and were accessed from http://ftp.tugraz.at/outgoing/ITSG/GRACE/ITSG-Grace2018/monthly/.

\subsection{Gravity Field Models Obtained from Kinematic Orbits of the LEO Satellites}

In this study, we used several temporal models of Earth's gravity field, developed based on the hl-SST method which uses kinematic orbits of LEO satellites, and provided by scientists from ITSG [5,6]. Among these models, there are series that use orbits of either gravimetric satellites (dedicated to gravity field determination) or satellites of which the main goals are not monitoring the gravity field (non-dedicated satellites). The models are based on orbits of one or few satellites of the same type. The institute also provides solutions that combine satellite data of different types. Summary information about satellites used by ITSG to develop gravity field models, including satellite type, 
mission duration, and orbit altitude and inclination, is included in Table 1. The data are publicly available to all users via http://ftp.tugraz.at/outgoing/ITSG/tvgogo/gravityFieldModels/.

Alternative data sets used in this study are models based on GRACE and Swarm satellite orbits, developed by ASU CAS [7,9], accessed from http://www.asu.cas.cz/ \{\}bezdek/vyzkum/geopotencial/ index.php.

Based on the data length and the considered time period, which should cover both time gap between GRACE and GRACE-FO (to potentially fill this gap) and at least the part of an operational period of the GRACE mission (to enable validation of models using the reference GRACE ITSG 2018 model), we selected twelve models from ITSG, Graz University of Technology and two models from ASU CAS, Prague (Table 2). All GRACE solutions considered here were based on a combination of both GRACE A and GRACE B orbits, while all Swarm solutions were developed using a combination of Swarm A, Swarm B, and Swarm C orbits. We also considered two combined solutions, Combined v2 and Combined v3, which used data from several types of satellites, as listed in Table 3. The rest of the solutions considered were developed based on observations from a single satellite. To distinguish between GRACE-based and Swarm-based models from Graz and Prague, the former and the latter will be further abbreviated with ITSG and CAS, respectively. The models from other satellites and combined models were provided by ITSG only.

All models had the same form as the reference ITSG 2018 series, namely time series of spherical harmonic coefficients with the monthly time resolution and maximum degree and order 60 (with one exception for GRACE A, B ITSG v2 for which the maximum d/o is equal to 100).

The $\left(\chi_{1}, \chi_{2}\right)$ components of HAM functions (both from models based on kinematic orbits of LEO satellites and GRACE ITSG 2018 reference solution) were computed from $\left(\mathrm{C}_{21}, \mathrm{~S}_{21}\right)$ coefficients of geopotential using the following formulas [24]:

$$
\begin{aligned}
& \chi_{1}=-\sqrt{\frac{5}{3}} \cdot \frac{1.608 \cdot R_{\mathrm{e}}^{2} \cdot \mathrm{M}}{\mathrm{C}-\mathrm{A}^{\prime}} \Delta \mathrm{C}_{21}, \\
& \chi_{2}=-\sqrt{\frac{5}{3}} \cdot \frac{1.608 \cdot \mathrm{R}_{\mathrm{e}}^{2} \cdot \mathrm{M}}{\mathrm{C}-\mathrm{A}^{\prime}} \Delta \mathrm{S}_{21},
\end{aligned}
$$

where $\Delta C_{21}$ and $\Delta S_{21}$ are the changes of coefficients of the Earth's gravity field; $R_{e}$ and $M$ are the Earth's mean radius $(6,378,136.6 \mathrm{~m})$ and mass $\left(5.9737 \times 10^{24} \mathrm{~kg}\right)$, respectively; $\mathrm{A}=8.0101 \times 10^{37} \mathrm{~kg} \cdot \mathrm{m}^{2}$, $\mathrm{B}=8.0103 \times 10^{37} \mathrm{~kg} \cdot \mathrm{m}^{2}$, and $\mathrm{C}=8.0365 \times 10^{37} \mathrm{~kg} \cdot \mathrm{m}^{2}$ are the Earth's principal moments of inertia, and $\mathrm{A}^{\prime}=(\mathrm{A}+\mathrm{B}) / 2$ is the average of the equatorial Earth's principal moments of inertia (Table 1 in Reference [24]).

Table 1. Basic information on the satellites that were used by ITSG to develop temporal models of Earth gravity field: satellite type, mission duration, and orbit altitude and inclination.

\begin{tabular}{ccccc}
\hline Satellite & Satellite Type & Mission Duration & $\begin{array}{c}\text { Orbit } \\
\text { Altitude (km) }\end{array}$ & $\begin{array}{c}\text { Orbit } \\
\text { Inclination }\left(^{\circ}\right)\end{array}$ \\
\hline CHAMP & & $15 / 07 / 2000-19 / 09 / 2010$ & 454 & 87.18 \\
GRACE A \& B & Gravimetry satellites & $17 / 03 / 2002-27 / 10 / 2017$ & 485 & 89.00 \\
GOCE & & $17 / 03 / 2009-11 / 11 / 2013$ & 250 & 96.50 \\
\hline Swarm A \& B & \multirow{2}{*}{ Magnetic field satellites } & Since 22/11/2013 & 450 & 87.40 \\
Swarm C & & Since 22/11/2013 & 550 & 88.00 \\
\hline Jason 1 & \multirow{3}{*}{ Altimetry satellites } & 07/12/2001-03/07/2013 & 1336 & 66.00 \\
Jason 2 & Since 20/06/2008 & 1336 & 66.00 \\
Jason 3 & & Since 17/01/2016 & 1336 & 66.04 \\
\hline
\end{tabular}


Table 1. Cont.

\begin{tabular}{ccccc}
\hline Satellite & Satellite Type & Mission Duration & $\begin{array}{c}\text { Orbit } \\
\text { Altitude }(\mathbf{k m})\end{array}$ & $\begin{array}{c}\text { Orbit } \\
\left.\text { Inclination } \mathbf{(}^{\circ}\right)\end{array}$ \\
\hline TerraSAR-X & & Since 15/06/2007 & 515 & 97.44 \\
TanDEM-X & Radar satellites & Since 21/06/2010 & 515 & 97.44 \\
KOMPSAT-5 & & Since 22/08/2013 & 550 & 97.60 \\
\hline MetOp-A & Weather satellites & Since 19/10/2006 & 817 & 98.70 \\
MetOp-B & Since 17/09/2012 & 817 & 98.70 \\
\hline Sentinel 3A & Earth observation satellite & Since 16/02/2016 & 814 & 98.62 \\
\hline SAC-C & Scientific satellite & 21/11/2000-15/08/2013 & 705 & 98.20 \\
\hline C/NOFS & Technology satellite & $16 / 04 / 2008-28 / 11 / 2015$ & $405-80$ & 13 \\
\hline
\end{tabular}

Table 2. Earth gravity field models from kinematic orbits of low-Earth-orbit (LEO) satellites provided by ITSG and ASU CAS used in this study, together with data sources.

\begin{tabular}{cc}
\hline ITSG & ASU CAS \\
\hline GRACE AB ITSG v2 & GRACE AB CAS \\
GRACE AB ITSG v3 & Swarm ABC CAS \\
Combined v2 & \\
Combined v3 & \\
Swarm ABC ITSG v1 & \\
Swarm ABC ITSG v2 & \\
Swarm ABC ITSG v3 & \\
TanDEM-X & \\
TerraSAR-X & \\
Jason 2 & \\
MetOp-A & \\
MetOp-B & http://www.asu.cas.cz/ \{\}bezdek/ \\
\hline http://ftp.tugraz.at/outgoing/ITSG/ & vyzkum/geopotencial/index.php \\
tvgogo/gravityFieldModels/ & \\
\hline
\end{tabular}

Table 3. Satellites used by ITSG to develop combined models of Earth gravity field.

\begin{tabular}{cc}
\hline Model & Satellites Used \\
\hline \multirow{2}{*}{ Combined v2 } & $\begin{array}{c}\text { CHAMP, GRACE A \& B, GOCE, Swarm A, B \& C, Jason 1, Jason 2, } \\
\text { TerraSAR-X, TanDEM-X, MetOp-A, MetOp-B, SAC-C, and C/NOFS }\end{array}$ \\
\hline \multirow{2}{*}{ Combined v3 } & $\begin{array}{c}\text { GRACE A \& B, GOCE, Swarm A, B \& C, Jason 2, Jason 3, TerraSAR-X, } \\
\text { TanDEM-X, KOMPSAT-5, MetOp-A, MetOp-B, and Sentinel 3A }\end{array}$ \\
\hline
\end{tabular}

\section{Results and Discussion}

\subsection{Time Series and Trends}

Initially, we performed a comparative analysis of the HAM and GAO series, without considering specific oscillations. Because of the different time resolutions of analysed data ( $3 \mathrm{~h}$ for AAM and OAM, $24 \mathrm{~h}$ for GAM, and monthly for all gravity field models), we downsampled all series to monthly changes using a Gaussian filter with a full width at half maximum (FWHM) equal to 60 days.

The STD of the $\chi_{1}$ and $\chi_{2}$ components of GAO and different HAM functions (after removing linear trends) are provided in Table 4 . The data in Table 4 were supplemented by the time period of each solution and its length. Notably, there were differences in data length between the considered solutions. However, all missions that are not dedicated to monitoring the gravity field are still operational (see Table 1), and therefore, the data from these missions may be useful in filling the gap between GRACE and GRACE-FO. Table 4 indicates that the STDs of $\chi_{1}$ and $\chi_{2}$ PM excitation functions 
from reference GAO and ITSG 2018 data were overestimated by values from all hl-SST estimates. Unsurprisingly, the most compatible with the reference series were GRACE AB (the best from CAS), Combined v2, and Combined v3 solutions. It should be noted that both combined solutions included orbits of dedicated satellites, which greatly contributed to the high consistency with GAO and ITSG 2018. However, the STD consistent with those obtained for reference PM excitation functions was also detected for the Swarm solution from CAS (Swarm ABC CAS). Surprisingly, these good results were not found for the Swarm ABC ITSG solutions. The reason for these differences may be the fact that both institutes used different approaches during computation of their gravity field models, namely the acceleration approach [7] for CAS solution and the short-arc approach [54] for ITSG solutions. The series computed from Jason 2, MetOp-A, and MetOp-B data revealed much higher STDs of $\chi_{1}$ and $\chi_{2}$ than reference data and other missions. This may result from visibly higher orbital altitude for these satellites (see Table 1). The Jason 2 solution was also affected by a lower inclination, which produced polar gaps in the data. Reference [5] shows that the lower accuracy of GNSS positioning for Jason 2, MetOp-A, and MetOp-B satellites could also contribute. In general, the higher the orbit of the satellite, the higher the STD of the obtained PM excitation function, and this could result from the fact that solutions from these higher orbits were noisier than series based on data from lower orbits.

The linear trends of $\chi_{1}$ and $\chi_{2}$ components of GAO and different HAM functions are shown in Table 5. Because the considered series were available in different time periods and in different lengths, to make them comparable with the reference series, the trends in GAO and HAM from ITSG 2018 were computed for the full period of their availability and also for the time period of each evaluated solution. It was noticeable that the trends of reference series were strongly dependent on the considered time period. For GAO, the trends varied from +1.83 to +5.62 milliarcseconds mas/year for $\chi_{1}$ and from -0.60 to +3.39 mas/year for $\chi_{2}$. The trends of HAM functions computed from ITSG 2018 solutions had values between +5.76 and +9.74 mas/year for $\chi_{1}$ and between -5.49 and +1.25 mas/year for $\chi_{2}$. These non-negligible differences suggested that GAO and ITSG 2018 excitation functions were characterized by non-linear trends. Table 5 shows that the best compatibility with $\chi_{1}$ trends of the reference series can be provided by GRACE AB CAS, GRACE AB ITSG v2, Combined v2, Swarm ABC ITSG v2, and TerraSAR-X solutions. For $\chi_{2}$, this correspondence was noticeable for GRACE AB ITSG v3, Combined v2, Swarm ABC CAS, and Swarm ABC ITSG v3. The results showed that the Jason 2, MetOp-A and MetOp-B solutions, which were distinguished by the highest STDs in $\chi_{1}$ and $\chi_{2}$, also visibly overestimated the trends in GAO and ITSG 2018 HAM series. The results from GRACE and Swarm orbits gave clearly superior results to the data from other satellites. However, TerraSAR-X provided satisfactory results for the $\chi_{1}$ trend. It should be also emphasized that for $\chi_{2}$ there were some periods where trends for GAO and ITSG 2018 HAM differed from each other in terms of their signs, such as for 2003.12-2012.98, 2011.87-2016.47, 2013.87-2015.35, and 2013.12-2016.49. For the same periods, for $\chi_{2}$, HAM function from ITSG 2018 gave a visibly higher trend than GAO.

Table 4. Standard deviations (STDs) of $\chi_{1}$ and $\chi_{2}$ components of geodetic residuals (GAO) and different hydrological angular momentum (HAM) series. Note that series were available in different time periods (given in decimal years) and with different period lengths (given in years).

\begin{tabular}{ccccc}
\hline Data & Time Period & Period Length (year) & $\chi_{1}$ STD (mas) & $\chi_{2}$ STD (mas) \\
\hline GAO & $2000.00-2019.14$ & 19.14 & 8.08 & 9.76 \\
ITSG 2018 & $2002.28-2016.54$ & 14.26 & 5.56 & 8.12 \\
\hline GRACE AB CAS & $2002.28-2016.49$ & 14.21 & 15.06 & 14.47 \\
GRACE AB ITSG v2 & $2003.12-2012.98$ & 9.86 & 28.47 & 23.59 \\
GRACE AB ITSG v3 & $2011.37-2016.46$ & 5.09 & 23.37 & 20.04 \\
Combined v2 & $2002.29-2014.77$ & 12.48 & 19.93 & 20.51 \\
Combined v3 & $2011.37-2016.46$ & 5.09 & 17.93 & 17.57 \\
Swarm ABC CAS & $2013.95-2016.42$ & 2.46 & 18.49 & 15.85 \\
Swarm ABC ITSG v1 & $2013.87-2015.35$ & 1.48 & 28.79 & 47.46 \\
\hline
\end{tabular}


Table 4. Cont.

\begin{tabular}{ccccc}
\hline Data & Time Period & Period Length (year) & $\chi_{\mathbf{1}}$ STD (mas) & $\chi_{2}$ STD (mas) \\
\hline Swarm ABC ITSG v2 & $2013.87-2016.42$ & 2.55 & 21.87 & 35.75 \\
Swarm ABC ITSG v3 & $2013.87-2016.42$ & 2.55 & 60.99 & 95.38 \\
TanDEM-X & $2011.87-2016.47$ & 4.60 & 68.28 & 88.66 \\
TerraSAR-X & $2011.37-2016.46$ & 5.09 & 54.10 & 60.62 \\
Jason 2 & $2011.37-2016.46$ & 5.09 & 1078.70 & 960.27 \\
MetOp-A & $2011.37-2016.46$ & 5.09 & 1320.95 & 729.69 \\
MetOp-B & $2013.12-2016.49$ & 3.37 & 1088.38 & 1183.26 \\
\hline
\end{tabular}

Table 5. Linear trends of $\chi_{1}$ and $\chi_{2}$ components of GAO and different HAM series. Note that series were available in different time periods (given in decimal years) and with different period lengths (given in years). The trends of reference series (GAO, ITSG 2018) were computed for all periods of evaluated series.

\begin{tabular}{ccccc}
\hline Data & Time Period & Period Length $(\mathbf{y r )})$ & $\begin{array}{c}\chi_{1} \text { Trend } \\
\text { LEO/GAO/ITSG2018 } \\
\text { (mas/year) }\end{array}$ & $\begin{array}{c}\chi_{2} \text { Trend } \\
\text { LEO/GAO/ITSG2018 } \\
\text { (mas/year) }\end{array}$ \\
\hline GAO & $2000.00-2019.14$ & 19.14 & 4.84 & -0.72 \\
ITSG 2018 & $2002.28-2016.54$ & 14.26 & 6.88 & -2.29 \\
\hline GRACE AB CAS & $2002.28-2016.49$ & 14.21 & $8.91 / 5.32 / 6.90$ & $0.69 /-0.17 /-2.29$ \\
GRACE AB ITSG v2 & $2003.12-2012.98$ & 9.86 & $4.88 / 5.62 / 7.59$ & $-0.70 / 0.44 /-1.18$ \\
GRACE AB ITSG v3 & $2011.37-2016.46$ & 5.09 & $14.2 / 4.65 / 5.99$ & $-2.80 /-0.60 /-5.49$ \\
Combined v2 & $2002.29-2014.77$ & 12.48 & $5.07 / 5.43 / 6.87$ & $-1.83 /-0.31 /-2.08$ \\
Combined v3 & $2011.37-2016.46$ & 5.09 & $12.59 / 4.65 / 5.99$ & $-2.40 /-0.60 /-5.49$ \\
Swarm ABC CAS & $2013.95-2016.42$ & 2.46 & $16.84 / 1.83 / 9.64$ & $3.18 / 3.16 / 1.25$ \\
Swarm ABC ITSG v1 & $2013.87-2015.35$ & 1.48 & $-5.22 / 2.72 / 9.74$ & $-31.46 / 1.09 /-5.43$ \\
Swarm ABC ITSG v2 & $2013.87-2016.42$ & 2.55 & $5.82 / 2.21 / 9.61$ & $-27.68 / 2.96 / 1.04$ \\
Swarm ABC ITSG v3 & $2013.87-2016.42$ & 2.55 & $22.49 / 2.21 / 9.61$ & $9.02 / 2.96 / 1.04$ \\
TanDEM-X & $2011.87-2016.47$ & 4.60 & $31.78 / 4.28 / 5.76$ & $-26.96 / 0.03 /-4.88$ \\
TerraSAR-X & $2011.37-2016.46$ & 5.09 & $7.36 / 4.65 / 5.99$ & $11.56 /-0.60 /-5.49$ \\
Jason 2 & $2011.37-2016.46$ & 5.09 & $-103.54 / 4.65 / 5.99$ & $-120.27 /-0.60 /-5.49$ \\
MetOp-A & $2011.37-2016.46$ & 5.09 & $-254.74 / 4.65 / 5.99$ & $-68.57 /-0.60 /-5.49$ \\
MetOp-B & $2013.12-2016.49$ & 3.37 & $118.1 / 3.01 / 7.15$ & $544.35 / 3.39 /-1.06$ \\
\hline
\end{tabular}

\subsection{Seasonal Variations}

We now extended our assessment of HAM series into seasonal oscillations. To calculate these seasonal changes, we first removed linear trends from the time series. Then, the seasonal variations were computed using the least squares method [33]. The fitted model included a sum of sinusoids with the periods of $365.25,182.625$, and 121.75 days.

The time series of seasonal changes (sum of annual, semi-annual, and ter-annual oscillations) in GAO HAM are shown in Figure 1 (for all GRACE and combined solutions) and in Figure 2 (for Swarm, TerraSAR-X, and TanDEM-X solutions). The MetOp-A, MetOp-B, and Jason 2 solutions were excluded from further analyses because of the poor STD agreement and trend inconsistency with reference data.

As shown in Figure 1, for $\chi_{1}$, only ITSG 2018 and GRACE AB ITSG v3 provided good phase agreement with GAO, while the best amplitude agreement was detected for Combined v3 solution. Almost all GRACE models, both from ll-SST and hl-SST estimates (GRACE AB CAS, GRACE AB ITSG v3, and ITSG 2018), notably underestimated seasonal variation in GAO. For $\chi_{2}$, very good phase agreement was found between all PM excitation series. The most consistent with GAO in terms of $\chi_{2}$ amplitudes was the GRACE AB ITSG v2 solution. Notably, the newest solutions from ITSG (GRACE AB ITSG v3 and Combined v3) visibly overestimated amplitudes of GAO in $\chi_{2}$, whereas GRACE AB CAS underestimated amplitudes of GAO in $\chi_{2}$. In general, better phase agreement with GAO was obtained for $\chi_{2}$ component and this was also observed in previous works, e.g., in References [26,28-30,32,37,55]. This resulted from spatial distribution of land and ocean that determine $\chi_{2}$ to be more sensitive to mass changes over land, and $\chi_{1}$ to be more sensitive to mass changes over ocean, ice, and glaciers. 
Figure 2 shows that, apart from Swarm ABC CAS and Swarm ABC ITSG v2, all hl-SST solutions from non-dedicated satellites visibly overestimated seasonal amplitudes of GAO for both $\chi_{1}$ and $\chi_{2}$ components. Moreover, for TanDEM-X and TerraSAR-X, the semi-annual $\chi_{2}$ changes were almost as strong as annual ones. For $\chi_{1}$, this was apparent for the Swarm ABC ITSG v3 data. For geodetic observations of PM excitation, however, the seasonal signal was notably stronger than semi-annual and ter-annual signals. In general, for both $\chi_{1}$ and $\chi_{2}$, the best amplitude and phase agreement with GAO and ITSG 2018 provided Swarm ABC CAS. Surprisingly, the former Swarm ABC ITSG v2 solution provided better amplitude agreement with GAO than the newer Swarm ABC ITSG v3.

The correlation coefficients between seasonal changes in GAO and HAM are shown in Figure 3. Because of different data lengths of the different series, we considered three periods: 2003-2013 (for GRACE AB CAS, GRACE AB ITSG v2, and Combined v2); 2011-2016 (for GRACE AB ITSG v3 and Combined v3); and 2014-2016 (for Swarm ABC CAS, Swarm ABC ITSG v2, Swarm ABC ITSG v3, TerraSAR-X, and TanDEM-X). To compare the results with those obtained for the reference GRACE ITSG 2018 solution, we also computed correlations between HAM functions from ITSG 2018 and GAO for the three considered time periods.

Keeping in mind that even high correlation between two time series can be statistically insignificant, for an objective assessment of the correlations, we determined the critical value of correlation coefficients. For this purpose, we used the autocorrelation function and the number of independent points. The autocorrelation function describes how a time series correlates with itself over different timescales. In other words, this function shows how rapidly time series changes or how rapidly it "forgets" about its previous values [56,57]. Therefore, the autocorrelation function measures for what time lag the correlation between series and between the same series but shifted with a lag will be close to zero (for what time shift time series become decorrelated). The decorrelation time are usually assumed as: (1) time required for autocorrelation function drop to the first zero-crossing, (2) twice the time required for autocorrelation function drop to $1 / 2$, (3) the time required for autocorrelation function drop to 1/e, and (4) twice the time required for autocorrelation function drop to 1/e [56,57]. The autocorrelation function is symmetric about zero. To compute the critical value of correlation coefficient for the assumed significance level, the number of degrees of freedom (or number of independent points) has to be computed. This number can be calculated by dividing the number of series points by the decorrelation time. Then, the critical value of correlation coefficient for the computed number of independent points and assumed significance level can be read from statistical tables.

In this work, we estimated the number of independent points required for the autocorrelation function to drop to 1/e [54]. Next, based on Student's $t$-test and a chosen significance level equal to 0.95 , we determined the critical value of the correlation coefficient for three considered periods separately. For the period 2003-2013, we obtained 47 independent points and a critical value of correlation coefficient equal to 0.24 ; for 2011-2016, 25 independent points and a correlation coefficient equal to 0.34; and for 2014-2016, 12 independent points and a correlation coefficient equal to 0.50.

The correlations between seasonal GAO and seasonal HAM from ITSG 2018 did not depend on the time period considered (Figure 3). Similar to amplitude and phase agreement shown in Figures 1 and 2 and results shown in previous works [26,28-30,32,37,55], visibly better correlations were obtained for $\chi_{2}$. This was also observed for almost all hl-SST solutions. Notably, all Swarm solutions and TanDEM-X data revealed better consistency with GAO for $\chi_{1}$ than for $\chi_{2}$. It was not surprising that the best correlation agreement with GAO was provided by the 1l-SST solution from ITSG 2018. However, GRACE AB ITSG v3 and Swarm ABC CAS data gave correlations of a similar size. Nevertheless, taking into consideration critical values of correlation coefficient for different time periods, for $\chi_{2}$, HAM from Swarm ABC CAS was almost insignificant. The Swarm models provided by ITSG were apparently inferior to the Swarm ABC CAS in terms of their correlations with observed PM excitation. We also noted that combined and Swarm solutions from ITSG did not improve in the latest releases (v3) compared with former ones (v2). This may be caused by the different time periods considered. Newer combined solutions were also shorter and were obtained from orbits of slightly different 
satellites than the previous combined v2 model (see Table 3). The decrease of accuracy in Swarm ABC ITSG v3 and GRACE AB ITSG v3 was especially visible for $\chi_{1}$. Regarding HAM computed from SAR satellites, both TerraSAR-X and TanDEM-X solutions did not provide satisfactory correlations with GAO, and only $\chi_{2}$ from the TerraSAR-X was well correlated with $\chi_{2}$ from GAO. Taking into consideration all of the above findings, the Swarm ABC CAS model was the best candidate to provide seasonal PM excitation data for the period lacking observational data from GRACE/GRACE-FO.
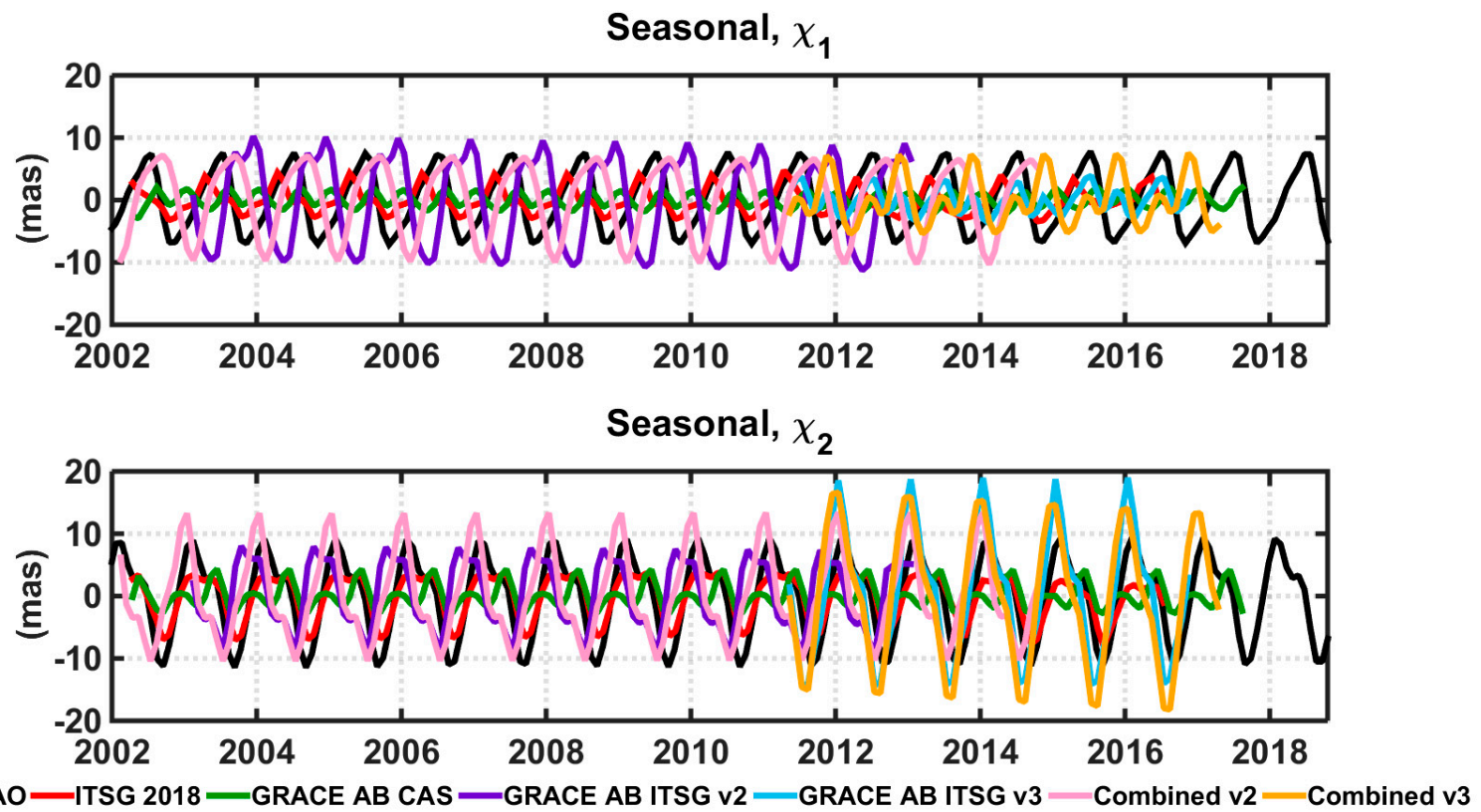

Figure 1. The $\chi_{1}$ and $\chi_{2}$ seasonal (sum of annual, semi-annual, and ter-annual) components GAO and HAM obtained from: (1) ITSG 2018 GRACE solution (low-low satellite-to-satellite tracking, 1l-SST), (2) solutions based on kinematic orbits of GRACE satellites (high-low satellite-to-satellite tracking, hl-SST), and (3) combined solutions (hl-SST).
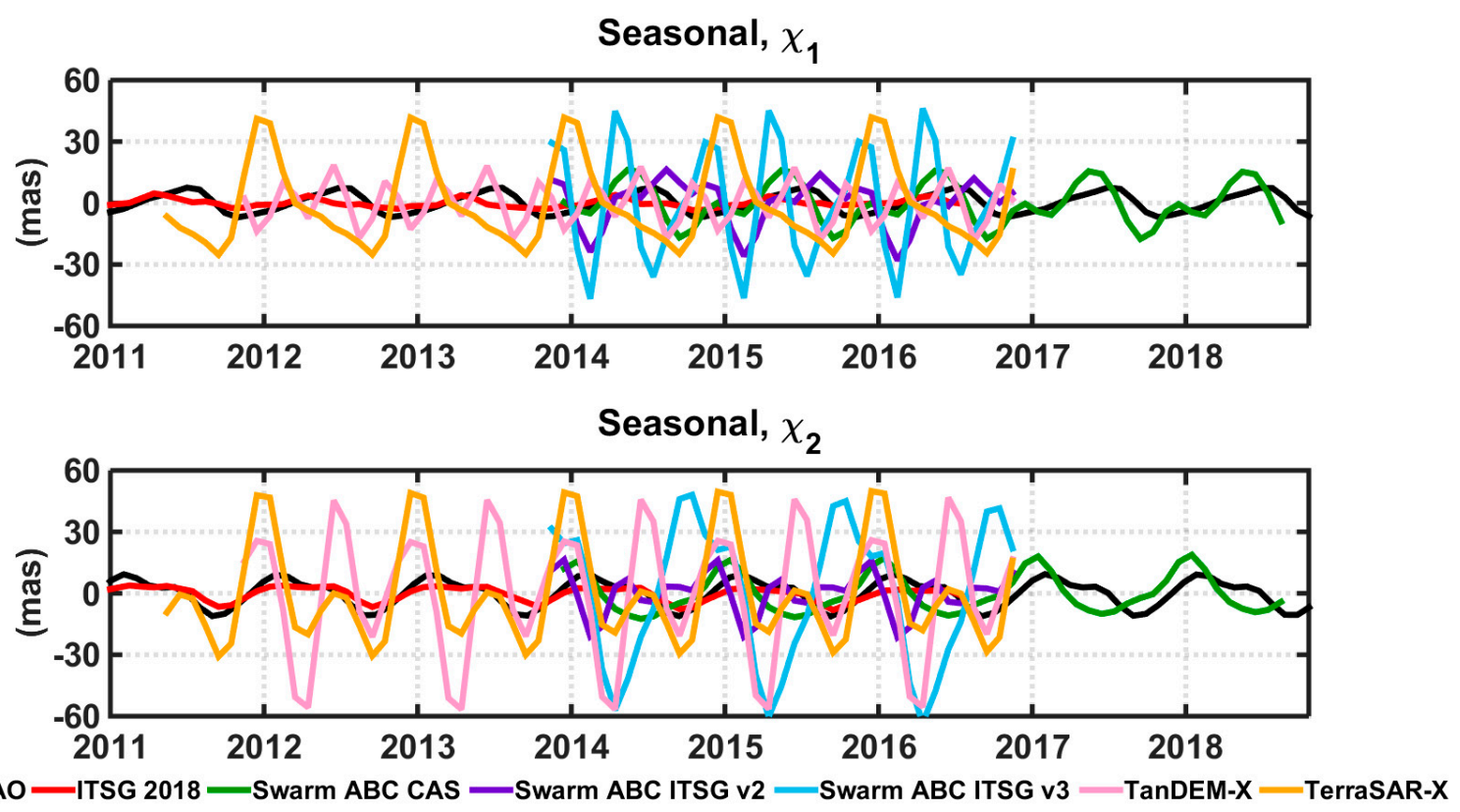

Figure 2. The $\chi_{1}$ and $\chi_{2}$ seasonal components of GAO and HAM obtained from: (1) ITSG 2018 GRACE solution (ll-SST), (2) solutions based on kinematic orbits of Swarm ABC, TanDEM-X, and TerraSAR-X satellites (hl-SST). 


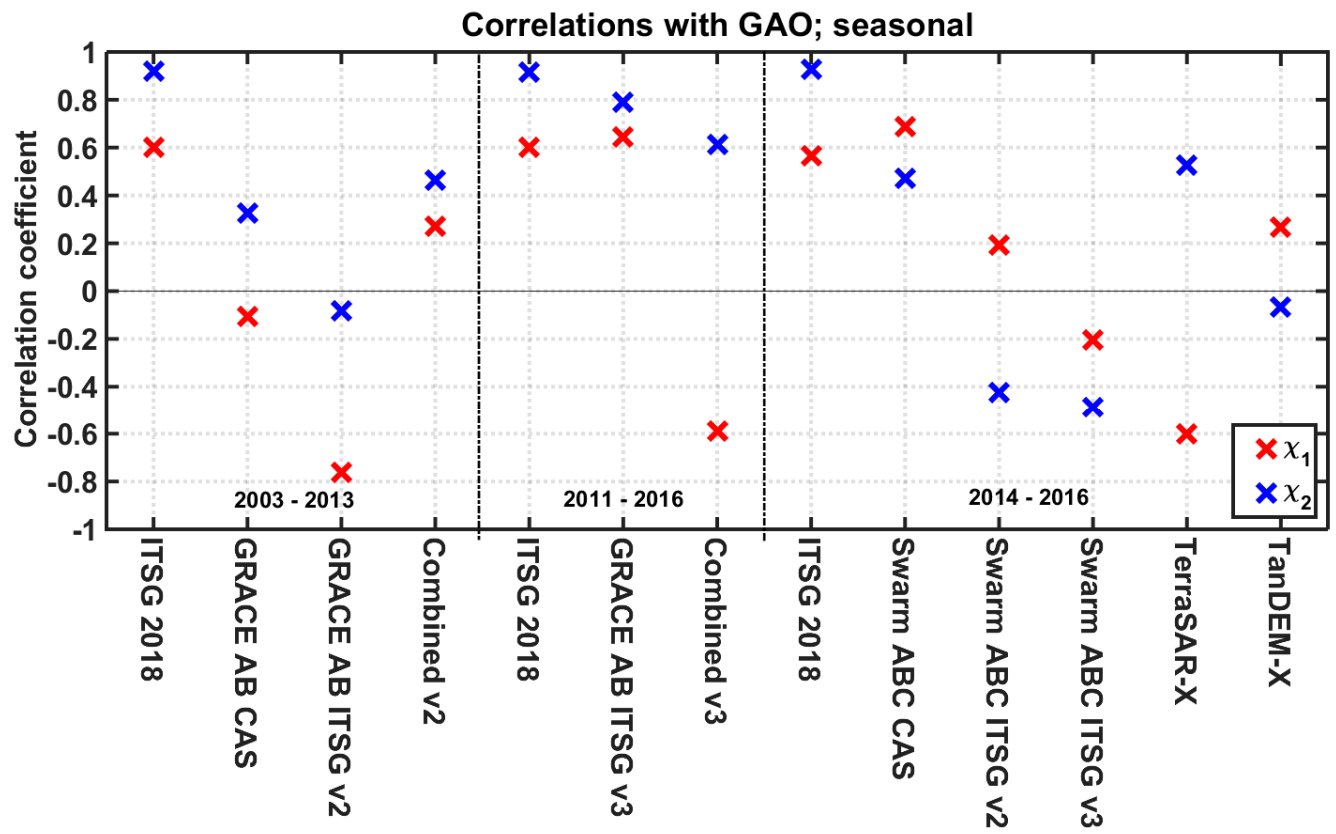

Figure 3. Correlation coefficients between seasonal changes of GAO and HAM obtained from ITSG 2018 GRACE solution (ll-SST) and solutions based on kinematic orbits of satellites (hl-SST). Because of the different data lengths of the series, we considered three periods: 2003-2013, 2011-2016, and 2013-2016. The critical values of correlation coefficient are equal to: 0.24 for 2003-2013, 0.34 for 2011-2016, and 0.50 for 2014-2016.

\subsection{Non-Seasonal Variations}

This section addresses the analysis of non-seasonal variations in GAO and HAM, which were obtained after removing linear trends and seasonal oscillations from the time series. The series of non-seasonal changes in GAO and HAM are shown in Figure 4 (for all GRACE and combined solutions) and in Figure 5 (for Swarm, TerraSAR-X, and TanDEM-X solutions).
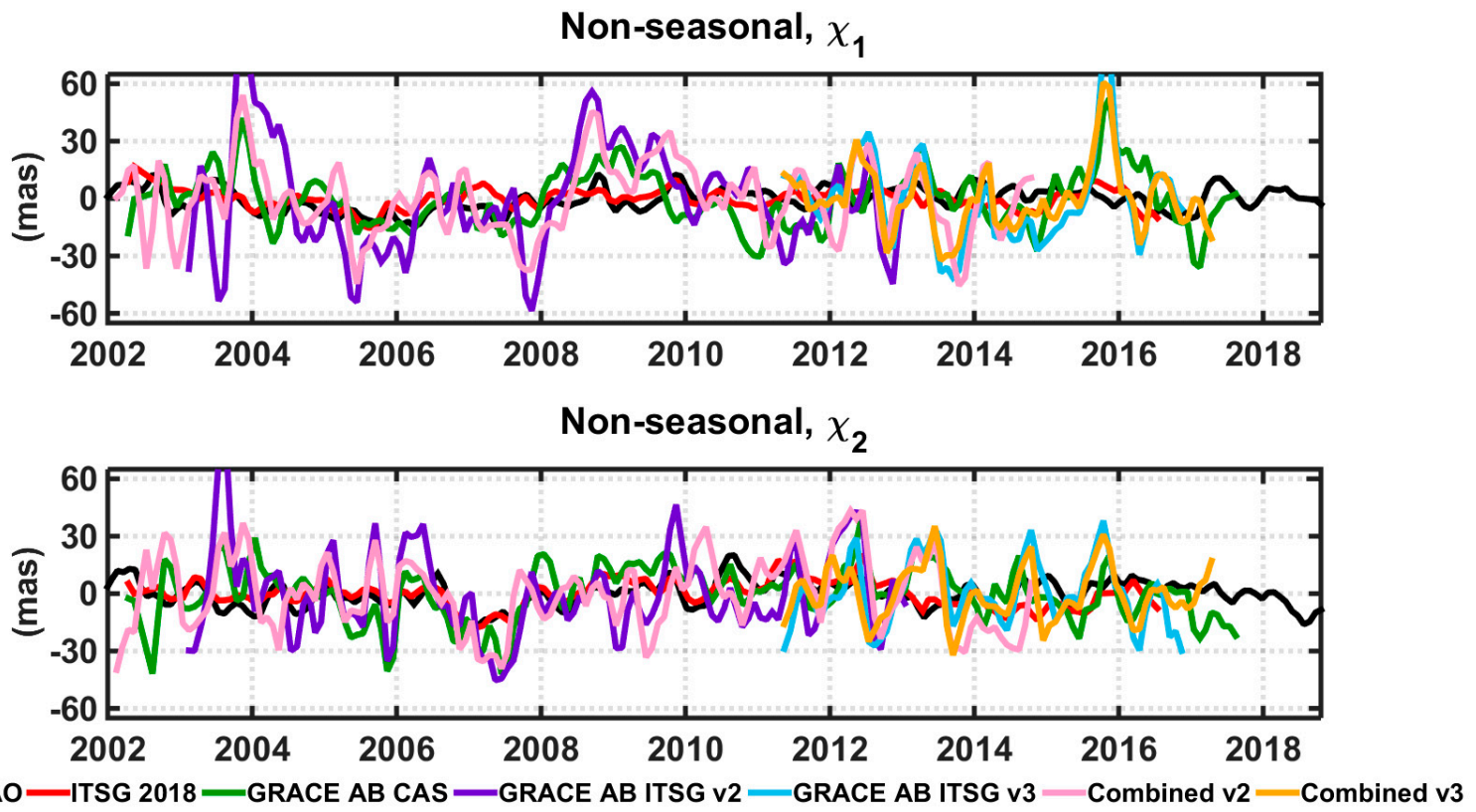

Figure 4. The $\chi_{1}$ and $\chi_{2}$ non-seasonal (after removing seasonal) components of GAO and HAM obtained from: (1) ITSG 2018 GRACE solution (ll-SST), (2) solutions based on kinematic orbits of GRACE satellites (hl-SST), and (3) combined solutions (hl-SST). 

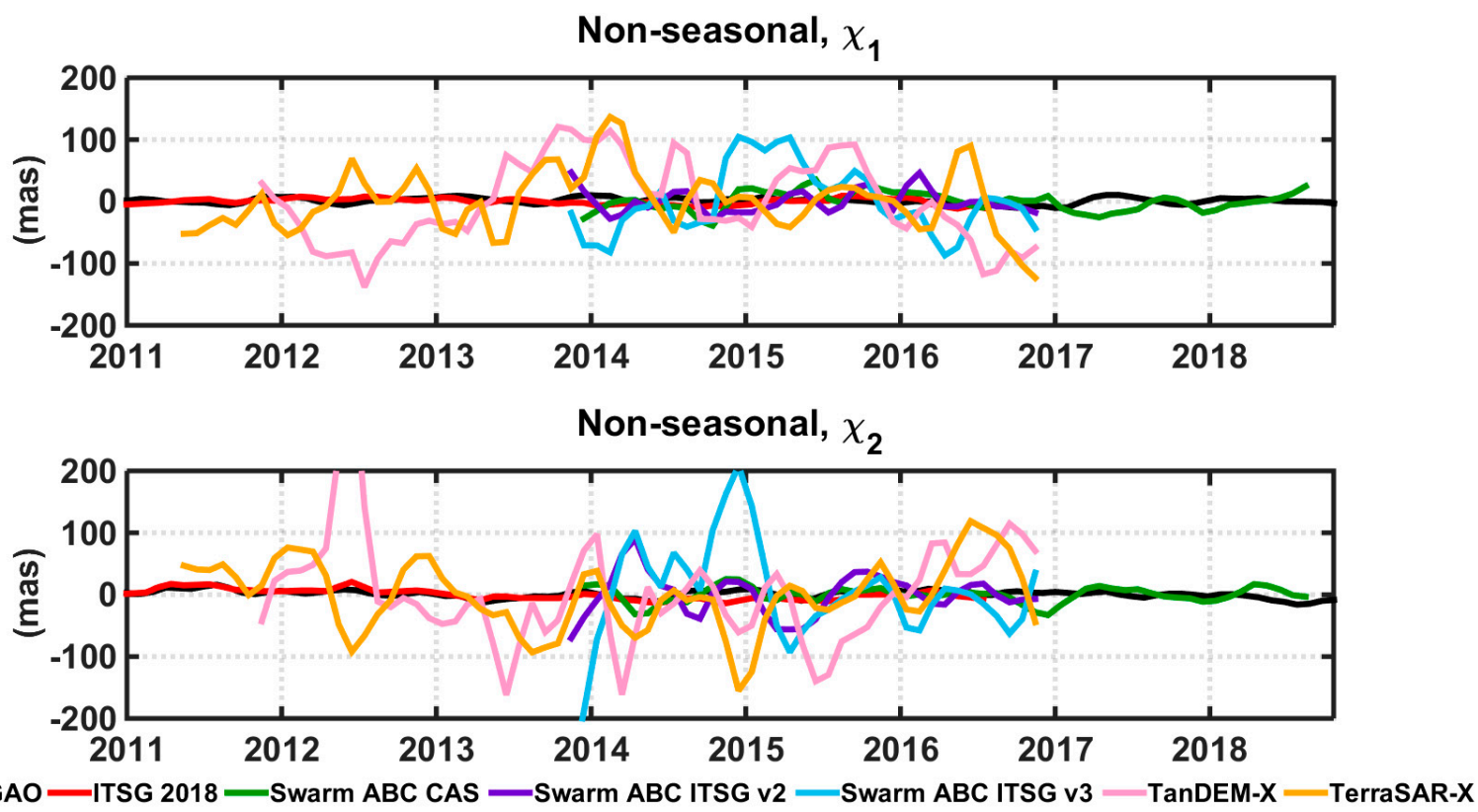

Figure 5. The $\chi_{1}$ and $\chi_{2}$ non-seasonal components of GAO and HAM obtained from: (1) ITSG 2018 GRACE solution (ll-SST), and (2) solutions based on kinematic orbits of Swarm ABC, TanDEM-X, and TerraSAR-X satellites (hl-SST).

Figure 4 shows that there is a very good consistency in terms of $\chi_{1}$ and $\chi_{2}$ amplitudes and phases between all hl-SST GRACE and combined solutions. However, all of them visibly overestimated amplitudes of reference PM excitation functions. Similar to the seasonal changes, HAM computed using GRACE AB CAS was distinguished by smaller amplitudes than the HAM obtained from the remaining hl-SST models. There were some periods in which evaluated models agreed in phase with the reference series, such as the same maximum in 2009 and minimum in 2005-2006 detected for $\chi_{1}$, or the same minimum in 2007 observed for $\chi_{2}$. Nevertheless, the considerable differences in the magnitude of amplitudes made this assessment difficult. Therefore, it is difficult to indicate the hl-SST solution that gives the best results. Even higher amplitudes were obtained for excitation functions computed using Swarm, TerraSAR-X and TanDEM-X data (Figure 5). Among all models based on orbits of non-dedicated satellites, only Swarm ABC CAS provided good amplitude and phase agreement with the reference series.

The correlation coefficients between non-seasonal changes in GAO and HAM are shown in Figure 6 . For the period 2003-2013 we obtained 29 independent points and a critical value of correlation coefficient equal to 0.31 ; for 2011-2016, 21 independent points and a correlation coefficient equal to 0.37; and for 2014-2016, 12 independent points and a correlation coefficient equal to 0.50 . In comparison to the values given in Figure 3, the differences in correlations with GAO between $\chi_{1}$ and $\chi_{2}$ were not as large as those of seasonal changes. In contrast to the seasonal spectral band, the size of correlation between GAO and HAM from the ITSG 2018 solution depended on the time period considered and was highest for 2003-2013. In 2003-2013 and 2011-2016, unsurprisingly, HAM functions from ITSG 2018 were best correlated with the observed PM excitation function. However, in 2014-2016, Swarm ABC CAS and TanDEM-X models revealed better results than ITSG 2018. Moreover, correlations were negative for both $\chi_{1}$ and $\chi_{2}$ only for HAM series obtained from TerraSAR-X solution. Nevertheless, taking into consideration the critical value of correlation coefficient for this short period, only $\chi_{2}$ from Swarm ABC CAS and ITSG 2018 and $\chi_{1}$ from TanDEM- $X$ were significantly correlated with GAO. It should be kept in mind that the years 2014-2017 were the last of the whole 15-year period of the GRACE mission duration. In this period, because of factors such as limited power availability for thermal control resulting from battery issues, the accuracy of GRACE solutions might have been lower than for the earlier years. This may be a reason why Swarm ABC CAS and TanDEM-X models 
performed higher correlation consistency with GAO than ITSG 2018. However, it should be kept in mind that HAM functions from TanDEM- $X$ data, although they provide high correlation coefficients with reference series, provide very big residual Root Mean Square RMS compared to GAO and HAM from ITSG 2018. Notably, HAM functions from GRACE, Swarm, and combined solutions provided by ITSG revealed decreased correlation agreement with GAO in the v3 release compared with in the former v2 release, and this might be an effect of different time periods and data lengths. Taking into consideration all of the above findings, the best candidate to provide non-seasonal PM excitation data for the period of lack of observational data from GRACE/GRACE-FO is the Swarm ABC CAS model.

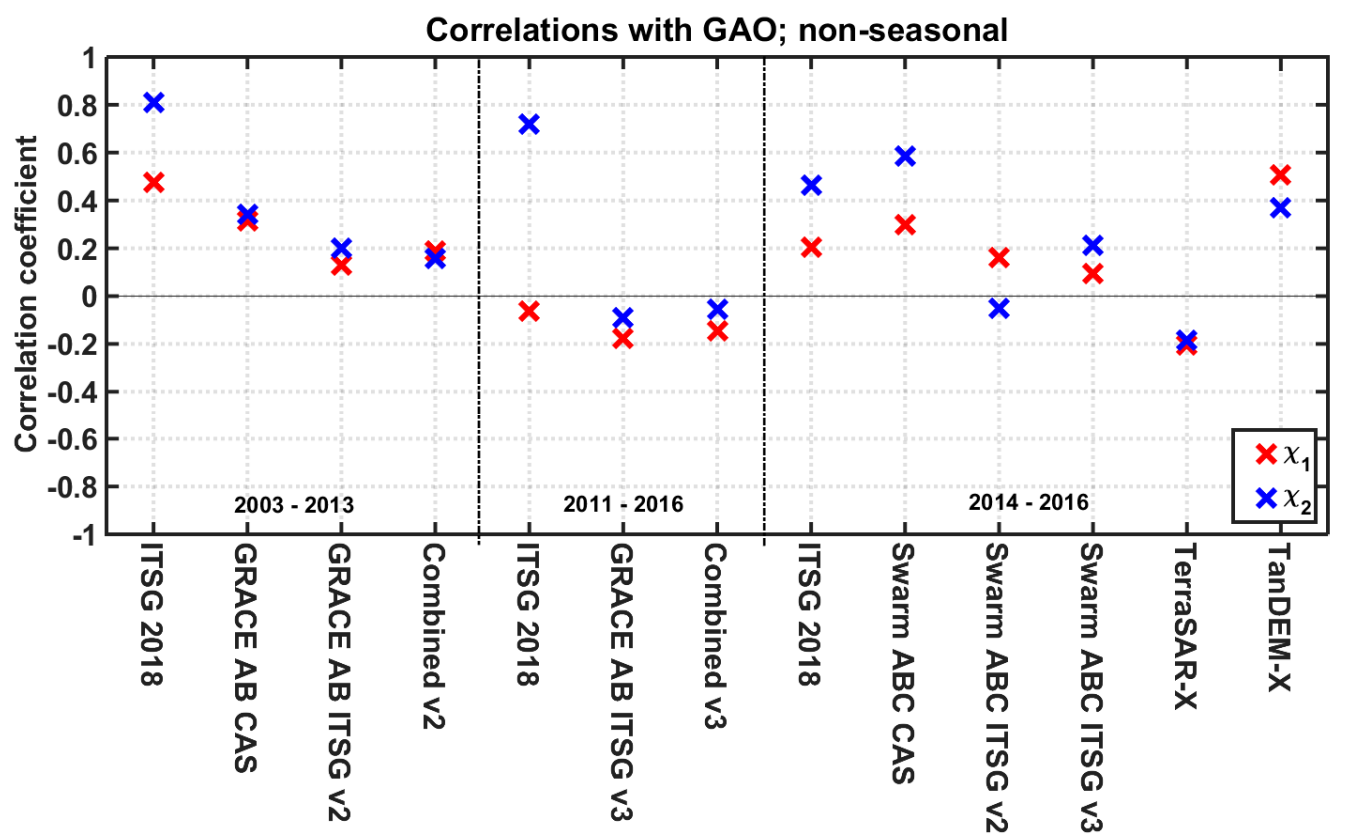

Figure 6. Correlation coefficients between non-seasonal changes of GAO and HAM obtained from ITSG 2018 GRACE solution (ll-SST) and solutions based on kinematic orbits of satellites (hl-SST). Because of the different data lengths of the series, we considered three periods: 2003-2013, 2011-2016, and 2013-2016. The critical values of correlation coefficient are equal to: 0.31 for 2003-2013, 0.37 for 2011-2016, and 0.50 for 2014-2016.

\section{Summary and Conclusions}

In this study, we evaluated HAM computed using gravity field models determined from hl-SST of the orbits of LEO satellites (GRACE, Swarm, TerraSAR-X, TanDEM-X, MetOp-A, MetOp-B, and Jason 2 ) and some combined solutions. The assessment was based on the comparison with GAO derived from precise measurements of the pole coordinates and with the latest GRACE ITSG 2018 solution. The STD of the HAM series, trends, and seasonal and non-seasonal changes were considered [58].

The results indicated that HAM excitation functions obtained from hl-SST solutions visibly overestimated the magnitude of amplitudes and STD of the reference series. In general, use of a satellite with a higher orbital altitude led to a higher STD of the HAM series obtained from its orbit. However, an objective evaluation of hl-SST solutions was difficult because of the short period of common data.

The comparison of trends revealed a considerable dependence of trend values in the reference data from the period considered, which suggested a non-linear character of trends in PM excitation. Apart from hl-SST solutions obtained from GRACE orbits and from combined data, the most compatible with GAO and HAM ITSG 2018 in terms of trends were series computed from Swarm ABC ITSG v2 and TerraSAR-X for $\chi_{1}$ and Swarm ABC CAS and Swarm ABC ITSG v3 for $\chi_{2}$. For HAM series computed using MetOp-A, MetOp-B, and Jason 2 satellite data, we reported visibly stronger amplitudes than for other HAM series, as well as trends that did not match the trends in reference data. The reasons 
for this were probably due to the higher orbital altitude and less accurate GNSS data than for other considered missions.

Among the HAM series computed using solutions obtained from satellites not dedicated to gravity field monitoring, only HAM Swarm ABC CAS proved to be sufficiently consistent with seasonal signal in reference data. For non-seasonal change, the $\chi_{1}$ and $\chi_{2}$ correlations with reference data were found to be more consistent with each other than in the seasonal spectral band. For non-seasonal oscillations, Swarm ABC CAS and TanDEM-X models were found to be the most appropriate to replace PM observations of the GRACE/GRACE-FO missions. However, it should be kept in mind that for the short time period considered here, the correlation coefficients, although high, are almost insignificant statistically. Nevertheless, an analysis of correlation coefficients provides a general overview that indicates that HAM series are superior to the others. Our results also showed that the level of correlation between non-seasonal changes in GAO and HAM obtained from the latest ITSG 2018 solution was dependent on the time period considered, and was the lowest for the last three years of the GRACE mission duration.

We noted that the Swarm ABC CAS solution revealed visibly better HAM consistency of seasonal and non-seasonal changes with GAO than Swarm models developed by ITSG (Swarm ABC ITSG v2 and Swarm ABC ITSG v3 solutions). The reason for such discrepancies might be differences in gravity field estimation approaches or different background models used. Similarly, seasonal and non-seasonal HAM changes obtained from GRACE AB CAS were better correlated with GAO than the corresponding HAM computed using the GRACE AB ITSG v2 model.

The comparison of HAM obtained from GRACE AB v2 and v3, Swarm ABC v2 and v3, and Combined v2 and v3 solutions provided by ITSG demonstrated that most of the newest v3 releases did not considerably improve the accuracy of the determined PM excitation compared with the former v2 series. Notably, for seasonal variations, Swarm and combined solutions revealed decreased accuracy, while for non-seasonal changes, only the $\chi_{2}$ component in HAM from the Swarm data had improved correlation with GAO. We suggest that the main reason why HAM from GRACE v3 solution is not clearly superior to the HAM obtained from GRACE v2 solution was the different time periods-in contrast to GRACE v2, the GRACE v3 model was developed for the period including the last few years of the mission when the accuracy of the GRACE measurements was lower. This decreased quality of GRACE data might also contribute to the lower accuracy of Combined v3 solution compared with that of Combined v2, as GRACE orbits were used in creating these models. Moreover, the Combined v2 and Combined v3 models were developed based on the orbits of different satellites. In particular, the Combined v2 solution was obtained from orbits of four satellites solely dedicated to the gravity field monitoring (CHAMP, GRACE A, GRACE B, and GOCE), whereas for Combined v3, only three such satellites were used (CHAMP was excluded). However, both Swarm ABC ITSG v2 and Swarm ABC ITSG v3 solutions were determined for the same time period but there were visible differences between them; seasonal, non-seasonal, and seasonal plus non-seasonal HAM variations revealed much bigger amplitudes and higher STD for Swarm v3 data, and differences in the trends were also visible. We assumed that the causes of such discrepancies may be updates to the processing algorithms or background models.

Overall, this study revealed that, as expected, neither of the considered hl-SST models provided the agreement with GAO at the same level of accuracy as ll-SST GRACE solutions. However, the Swarm data gave the most satisfactory results in both the seasonal and non-seasonal spectral bands. The problem of inconsistency between Swarm solutions from different processing centres can be overcome by combination of the different Swarm series. Some attempts to do so have been made by References [12,13]. However, they focused on analyses of geoid height [12] and global mass changes over ocean, continents, and ice sheets [13]. It is likely that such a combination of Swarm data will also lead to the increased consistency with geodetic observations of PM excitation. Nevertheless, detailed analyses have not been conducted so far, and they will be a subject of our future work. 
Some high-quality information on PM excitation can be also obtained from the combination of data from different LEO satellites. In fact, the HAM functions computed from the Combined v2 and Combined v3 solutions considered here gave high correlation coefficients with GAO and satisfactory amplitude and STD agreement. However, these good results were mainly induced by including data from gravimetric satellites (CHAMP, GRACE, and GOCE). On the basis of these results, we concluded that the hydrological part of PM excitation can be derived from gravity field models obtained from kinematic orbits of LEO satellites. However, a notable impact on the accuracy of determined HAM has orbital parameters such as altitude and inclination, as well as computation approaches and algorithms and accuracy of GNSS observations. We identified that the best candidate to fill a PM data gap between GRACE and GRACE-FO are Swarm models provided by ASU CAS.

Author Contributions: Conceptualization, J.S. and J.N.; data curation, J.S.; formal analysis, J.N.; funding acquisition, J.S. and J.N.; investigation, J.S.; methodology, J.S. and J.N.; project administration, J.N.; resources, J.N.; software J.S.; supervision, J.N.; validation J.N.; visualization, J.S.; writing of the original draft, J.S.; writing of review and editing, J.N.

Funding: This research was funded by the National Science Centre, Poland (NCN), grant number 2018/31/N/ST10/00209 and the Polish National Agency for Academic Exchange (NAWA), grant number PPI/APM/2018/1/00032/U/001.

Acknowledgments: We thank Alex Boon of Soil Science Editing for editing a draft of this manuscript. We would like to thank three anonymous reviewers for their valuable comments.

Conflicts of Interest: The authors declare no conflicts of interest. The funders had no role in the design of the study; in the collection, analyses, or interpretation of data; in the writing of the manuscript, or in the decision to publish the results.

\section{References}

1. Tapley, B.D.; Bettadpur, S.; Watkins, M.; Reigber, C. The gravity recovery and climate experiment: Mission overview and early results. Geophys. Res. Lett. 2004, 31, 1-4. [CrossRef]

2. Tapley, B.D.; Watkins, M.M.; Flechtner, F.; Reigber, C.; Bettadpur, S.; Rodell, M.; Sasgen, I.; Famiglietti, J.S.; Landerer, F.W.; Chambers, D.P.; et al. Contributions of GRACE to understanding climate change. Nat. Clim. Chang. 2019, 9, 358-369. [CrossRef]

3. Balmino, G.; Perosanz, F.; Rummel, R.; Sneeuw, N.; Sunkel, H. CHAMP, GRACE and GOCE: Mission concepts and simulations. Bollettino Di Geofisica Teorica Ed Applicata 1999, 40, 309-319.

4. Keller, W. Satellite-to-Satellite Tracking (Low-Low/High-Low SST). In Handbook of Geomathematics; Springer: Berlin, Germany, 2015.

5. Zehentner, N.; Mayer-Gürr, T. Precise orbit determination based on raw GPS measurements. J. Geod. 2016, 90, 275-286. [CrossRef]

6. Zehentner, N. Kinematic Orbit Positioning Applying the Raw Observation Approach to Observe Time Variable Gravity. Ph.D. Thesis, Graz University of Technology, Graz, Austria, 2017.

7. Bezděk, A.; Sebera, J.; Klokočník, J.; Kostelecký, J. Gravity field models from kinematic orbits of CHAMP, GRACE and GOCE satellites. Adv. Space Res. 2014, 53, 412-429. [CrossRef]

8. Friis-Christensen, E.; Luhr, H.; Hulot, G. Swarm: A constellation to study the Earth's magnetic field. Earth Planets Space 2006, 58, 351-358. [CrossRef]

9. Bezděk, A.; Sebera, J.; Da Encarnação, J.T.; Klokočník, J. Time-variable gravity fields derived from GPS tracking of Swarm. Geophys. J. Int. 2016, 205, 1665-1669. [CrossRef]

10. Lück, C.; Kusche, J.; Rietbroek, R.; Löcher, A. Time-variable gravity fields and ocean mass change from 37 months of kinematic Swarm orbits. Solid Earth 2018, 9, 323-339. [CrossRef]

11. Jäggi, A.; Dahle, C.; Arnold, D.; Bock, H.; Meyer, U.; Beutler, G.; Ijssel, J.V.D. Swarm kinematic orbits and gravity fields from 18 months of GPS data. Adv. Space Res. 2016, 57, 218-233. [CrossRef]

12. Teixeira Da Encarnação, J.; Arnold, D.; Bezděk, A.; Dahle, C.; Doornbos, E.; Van Den Ijssel, J.; Jäggi, A.; Mayer-Gürr, T.; Sebera, J.; Visser, P.; et al. Gravity field models derived from Swarm GPS data Swarm. Earth Planet Space 2016, 68, 127. [CrossRef] 
13. Visser, P.; Teixeira da Encarnacao, J.; Doornbos, E.; van den Ijssel, J.; Mao, X.; Iorfida, E.; Arnold, D.; Jaeggi, A.; Meyer, U.; Bezdek, A.; et al. Complete 5-years time series of combined monthly gravity field models derived from Swarm GPS data. Geophys. Res. Abstr. 2019, 21. Available online: https://www.researchgate.net/publication/332656024_Complete_5-years_time_series_of_ combined_monthly_gravity_field_models_derived_from_Swarm_GPS_data (accessed on 11 April 2019).

14. Drinkwater, M.; Haagmans, R.; Muzi, D.; Popescu, A.; Floberghagen, R.; Kern, M.; Fehringer, M. The GOCE gravity mission: ESAS first core earth explorer. In Proceedings of the 3rd International GOCE User Workshop, Frascati, Italy, 6-8 November 2006.

15. Krieger, G.; Moreira, A.; Fiedler, H.; Hajnsek, I.; Werner, M.; Younis, M.; Zink, M. TanDEM-X: A Satellite Formation for High-Resolution SAR Interferometry. IEEE Trans. Geosci. Remote. Sens. 2007, 45, 3317-3341. [CrossRef]

16. Werninghaus, R.; Buckreuss, S.; Pitz, W. TerraSAR-X mission status. In Proceedings of the 2007 IEEE international geoscience and remote sensing symposium, Barcelona, Spain, 23-28 July 2007.

17. Edwards, P.G.; Berruti, B.; Blythe, P.; Callies, J.; Carlier, S.; Fransen, C.; Krutsch, R.; Lefebvre, A.R.; Loiselet, M.; Stricker, N. TheMetOp satellite-weather information from polar orbit. ESA Bull. 2006, 127, 8-17.

18. Rocken, C.; Kuo, Y.H.; Schreiner, W.; Hunt, D.; Sokolovskiy, S.; McCormick, C. COSMIC system description. Terr Atmos Ocean Sci. 2000, 11, 21-52. [CrossRef]

19. Bettadpur, S. UTCSR Level-2 Processing Standards Document for Level-2 Product Release 0005. Technical Report GRACE 2012. Available online: Ftp://podaac-ftp.jpl.nasa.gov/allData/grace/docs/L2-CSR0005_ ProcStd_v4.0.pdf (accessed on 31 March 2019).

20. Weigelt, M.; van Dam, T.; Baur, O.; Tourian, M.J.; Steffen, H.; Sosnica, K.; Jäggi, A.; Zehentner, N.; Mayer-Gürr, T.; Sneeuw, N. How well can the combination hISST and SLR replace GRACE? A discussion from the point of view of applications. In Proceedings of the Grace Science Team Meeting 2014, Potsdam, Germany, 1 October 2014.

21. Zehentner, N.; Mayer-Gürr, T.; Weigelt, M.; Jäggi, A. Non-dedicated satellite missions for time variable gravity field estimation. In Proceedings of the Grace Science Team Meeting 2014, Potsdam, Germany, 1 October 2014.

22. Zehentner, N.; Mayer-Gürr, T. SST-hl: Time variable gravity from multiple non-dedicated satellites. Geophys. Res. Abstr. 2015, 17. EGU2015-10613-1.

23. Weigelt, M.; Jäggi, A.; Meyer, U.; Arnold, D.; Grahsl, A.; Mayer-Gürr, T.; Zehentner, N.; Steffen, H.; Tourian, M.J.; Dahle, C.; et al. Hl-SST and SLR-bridging the gap between GRACE and GRACE Follow-On. In Proceedings of the 20th EGU General Assembly, Vienna, Austria, 4-13 April 2018. EGUGA2018-2013517.

24. Gross, R. Theory of earth rotation variations. In VIII Hotine-Marussi Symposium on Mathematical Geodesy; Sneeuw, N., Novák, P., Crespi, M., Sansò, F., Eds.; Springer: Cham, Switzerland, 2015; Volume 142.

25. Göttl, F.; Schmidt, M.; Seitz, F. Mass-related excitation of polar motion: An assessment of the new RL06 GRACE gravity field models. Earth Planets Space 2018, 70, 195. [CrossRef]

26. Meyrath, T.; Van Dam, T. A comparison of interannual hydrological polar motion excitation from GRACE and geodetic observations. J. Geodyn. 2016, 99, 1-9. [CrossRef]

27. Nastula, J.; Paśnicka, M.; Kołaczek, B. Comparison of the geophysical excitations of polar motion from the period: 1980.0-2009.0. Acta Geophys. 2011, 59, 561-577. [CrossRef]

28. Nastula, J.; Wińska, M.; Śliwińska, J.; Salstein, D. Hydrological signals in polar motion excitation-Evidence after fifteen years of the GRACE mission. J. Geodyn. 2019, 124, 119-132. [CrossRef]

29. Seoane, L.; Nastula, J.; Bizouard, C.; Gambis, D. Hydrological Excitation of Polar Motion Derived from GRACE Gravity Field Solutions. Int. J. Geophys. 2011, 2011, 1-10. [CrossRef]

30. Śliwińska, J.; Wińska, M.; Nastula, J. Terrestrial water storage variations and their effect on polar motion. Acta Geophys. 2019, 67, 17-39. [CrossRef]

31. Winska, M.; Nastula, J.; Salstein, D. Hydrological excitation of polar motion by different variables from the GLDAS models. J. Geod. 2017, 91, 1461-1473. [CrossRef]

32. Brzeziński, A.; Nastula, J.; Kołaczek, B.; Ponte, R.M. Oceanic excitation of polar motion from interannual to decadal periods. In Proceedings of the International Association of Geodesy. IAG General Assembly, Sapporo, Japan, 30 June-11 July 2003.

33. Brzeziński, A.; Nastula, J.; Kołaczek, B. Seasonal excitation of polar motion estimated from recent geophysical models and observations. J. Geodyn. 2009, 48, 235-240. [CrossRef] 
34. Gross, R.S.; Fukumori, I.; Menemenlis, D. Atmospheric and oceanic excitation of the Earth's wobbles during 1980-2000. J. Geophys. Res. Space Phys. 2003, 108. [CrossRef]

35. Nastula, J.; Ponte, R.M. Further evidence for oceanic excitation of polar motion. Geophys. J. Int. 1999, 139, 123-130. [CrossRef]

36. Nastula, J.; Ponte, R.M.; Salstein, D.A. Regional signals in atmospheric and oceanic excitation of polar motion. In Polar Motion: Historical and Scientific Problems; Dick, S., McCarthy, D., Luzum, B., Eds.; ASP: San Francisco, CA, USA, 2000; pp. 463-472, ISBN 1-58381-039-0.

37. Nastula, J.; Ponte, R.M.; Salstein, D.A. Comparison of polar motion excitation series derived from GRACE and from analyses of geophysical fluids. Geophys. Res. Lett. 2007, 34. [CrossRef]

38. Nastula, J.; Salstein, D.; Kolaczek, B. Patterns of atmospheric excitation functions of polar motion from high-resolution regional sectors. J. Geophys. Res. Space Phys. 2009, 114. [CrossRef]

39. Mayer-Gürr, T.; Behzadpour, S.; Ellmer, M.; Kvas, A.; Klinger, B.; Strasser, S.; Zehentner, N. ITSG-Grace2018-Monthly; Daily and Static Gravity Field Solutions from GRACE. GFZ Data Services. 2018. Available online: https://graz.pure.elsevier.com/de/publications/itsg-grace2018-monthly-daily-and-staticgravity-field-solutions-f (accessed on 4 December 2018).

40. Brzezinski, A. Polar motion excitation by variations of the effective angular momentum function: Considerations concerning deconvolution problem. Manuscr. Geod. 1992, 17, 3-20.

41. Eubanks, T.M. Variations in the orientation of the Earth. In Contributions of Space Geodesy to Geodynamics: Earth Dynamics: Geodynamic Series; Smith, D.E., Turcotte, D.L., Eds.; American Geophysical Union: Washington, DC, USA, 1993; Volume 24, pp. 1-54.

42. Bizouard, C.; Lambert, S.; Becker, O.; Richard, J.Y. Combined Solution C04 for Earth Rotation Parameters Consistent with International Terrestrial Reference Frame 2014. IERS Notice 2017. Available online: 145.238.203.2/eoppc/eop/eopc04/C04.guide.pdf (accessed on 9 January 2017).

43. Bizouard, C.; Lambert, S.; Gattano, C.; Becker, O.; Richard, J.-Y. The IERS EOP 14C04 solution for Earth orientation parameters consistent with ITRF 2014. J. Geod. 2018, 93, 621-633. [CrossRef]

44. Dobslaw, H.; Dill, R.; Grötzsch, A.; Brzezinski, A.; Thomas, M. Seasonal polar motion excitation from numerical models of atmosphere, ocean, and continental hydrosphere. J. Geophys. Res. Space Phys. 2010, 115. [CrossRef]

45. Dobslaw, H.; Bergmann-Wolf, I.; Dill, R.; Poropat, L.; Thomas, M.; Dahle, C.; Esselborn, S.; König, R.; Flechtner, F. A new high-resolution model of non-tidal atmosphere and ocean mass variability for de-aliasing of satellite gravity observations: AOD1B RL06. Geophys. J. Int. 2017, 211, 263-269. [CrossRef]

46. Dobslaw, H.; Bergmann-Wolf, I.; Dill, R.; Poropat, L.; Flechtner, F. Product description document for AOD1B release 06. Tech. Rep. GRACE 2017, 1, 327-750.

47. Jungclaus, J.H.; Fischer, N.; Haak, H.; Lohmann, K.; Marotzke, J.; Matei, D.; Mikolajewicz, U.; Notz, D.; von Storch, J.S. Characteristics of the ocean simulations in MPIOM; the ocean component of the MPI-Earth system model. J. Adv. Model. Earth Syst. 2013, 5, 422-446. [CrossRef]

48. Bettadpur, S. UTCSR Level-2 Processing Standards Document for Level-2 Product Release 0006. Technical Report GRACE 2018. Available online: Ftp://podaac-ftp.jpl.nasa.gov/allData/grace/docs/L2-CSR006_ProcStd_ v5.0.pdf (accessed on 31 March 2019).

49. Dahle, C.; Flechtner, F.; Murböck, M.; Michalak, G.; Neumayer, H.; Abrykosov, O.; Reinhold, A.; König, R. GFZ Level-2 Processing Standards Document for Level-2 Product Release 06. Scientific Technical Report STR-Data. 2019. Available online: Ftp://podaac.jpl.nasa.gov/GeodeticsGravity/grace/docs/L2-GFZ_ProcStds_ RL06_DRAFT.pdf (accessed on 18 March 2019).

50. Yuan, D. JPL Level-2 Processing Standards Document for Level-2 Product Release 06. Technical Report GRACE 2018; pp. 327-744. Available online: Ftp://podaac-ftp.jpl.nasa.gov/allData/grace/docs/L2-JPL_ ProcStds_v6.0.pdf (accessed on 30 March 2019).

51. Śliwińska, J.; Wińska, M.; Nastula, J. Comparison of geodetic hydrological excitation functions with new GRACE RL06 solutions and hydrological excitations. In Proceedings of the AGU Fall Meeting 2018, Washington, DC, USA, 10-14 December 2018.

52. Śliwińska, J.; Nastula, J. Polar motion excitation functions from GRACE RL05 and RL06 solutions. In Proceedings of the IUGG General Assembly 2019, Montreal, Canada, 8-18 July 2019.

53. Nastula, J.; Śliwińska, J. Estimating hydrological signal in polar motion from new GRACE RL06 solutions. In Proceedings of the IUGG General Assembly 2019, Montreal, Canada, 8-18 July 2019. 
54. Mayer-Gürr, T. Gravitationsfeldbestimmung aus der Analyse kurzer Bahnbögen am Beispiel der Satellitenmissionen CHAMP und GRACE. Ph.D. Thesis, University of Bonn, Bonn, Germany, January 2006.

55. Wińska, M.; Nastula, J.; Kołaczek, B. Assessment of the Global and Regional Land Hydrosphere and Its Impact on the Balance of the Geophysical Excitation Function of Polar Motion. Acta Geophys. 2016, 64, 270-292. [CrossRef]

56. De Viron, O.; Panet, I.; Diament, M. Extracting low frequency climate signal from GRACE data. eEarth 2006, 1, 9-14. [CrossRef]

57. Gille, S. UCSD-MAE 127: Statistical Methods for Environmental Sciences and Engineering, Lecture 10, University of California, San Diego, La Jolla, The United States. 2005. Available online: http://pordlabs.ucsd. edu/sgille/mae127/lecture10.pdf (accessed on 30 March 2019).

58. Śliwińska, J.; Nastula, J.; Wińska, M. Determination of hydrological signal in polar motion variations from gravity field models obtained from kinematic orbits of LEO satellites. In Proceedings of the European Geosciences Union (EGU) General Assembly 2019, Vienna, Austria, 7-12 April 2019.

(C) 2019 by the authors. Licensee MDPI, Basel, Switzerland. This article is an open access article distributed under the terms and conditions of the Creative Commons Attribution (CC BY) license (http://creativecommons.org/licenses/by/4.0/). 